University of Nebraska - Lincoln

DigitalCommons@University of Nebraska - Lincoln

USDA National Wildlife Research Center - Staff Publications
U.S. Department of Agriculture: Animal and Plant Health Inspection Service

2010

\title{
Raccoon (Procyon lotor) Movements and Dispersal Associated with Ridges and Valleys of Pennsylvania: Implications for Rabies Management
}

\author{
Robert B. Puskas \\ U.S. Department of Agriculture \\ Justin W. Fischer \\ USDA/APHIS/WS National Wildlife Research Center, Justin.w.fischer@aphis.usda.gov \\ Craig B. Swope \\ U.S. Department of Agriculture \\ Mike R. Dunbar \\ National Wildlife Research Center \\ Robert G. McLean \\ National Wildlife Research Center
}

See next page for additional authors

Follow this and additional works at: https://digitalcommons.unl.edu/icwdm_usdanwrc

Part of the Life Sciences Commons

Puskas, Robert B.; Fischer, Justin W.; Swope, Craig B.; Dunbar, Mike R.; McLean, Robert G.; and Root, J. Jeffrey, "Raccoon (Procyon lotor) Movements and Dispersal Associated with Ridges and Valleys of Pennsylvania: Implications for Rabies Management" (2010). USDA National Wildlife Research Center Staff Publications. 1265.

https://digitalcommons.unl.edu/icwdm_usdanwrc/1265

This Article is brought to you for free and open access by the U.S. Department of Agriculture: Animal and Plant Health Inspection Service at DigitalCommons@University of Nebraska - Lincoln. It has been accepted for inclusion in USDA National Wildlife Research Center - Staff Publications by an authorized administrator of DigitalCommons@University of Nebraska - Lincoln. 


\section{Authors}

Robert B. Puskas, Justin W. Fischer, Craig B. Swope, Mike R. Dunbar, Robert G. McLean, and J. Jeffrey Root 


\title{
Raccoon (Procyon lotor) Movements and Dispersal Associated with Ridges and Valleys of Pennsylvania: Implications for Rabies Management
}

\author{
Robert B. Puskas, Justin W. Fischer, ${ }^{2}$ Craig B. Swope, Mike R. Dunbar, \\ Robert G. McLean, ${ }^{2}$ and J. Jeffrey Root ${ }^{2}$
}

\begin{abstract}
The raccoon (Procyon lotor) continues to be a prominent terrestrial rabies reservoir in the eastern United States. Describing the dispersal and movements of these animals and determining geographic features that are natural hindrances or corridors to movements could be used to assist oral rabies vaccination efforts. The landscape of the ridge-and-valley system in Pennsylvania exhibits characteristics of both natural potential hindrances and travel corridors to the movements of wildlife. The movements of 49 raccoons were monitored throughout a ridge and two adjacent valley sites to assess their movements related to these landscape features. Results suggest that few raccoons cross the ridge we studied over the short-term and that long-distance movements of these animals are uncommon in this region. Consequently, movement corridors within the ridge were largely confined to spur valleys within the ridge system. These results may be useful in strategic oral rabies vaccination programs in Pennsylvania and other areas where natural hindrances and travel corridors to movement are identified.
\end{abstract}

Key Words: landscape—movements—Pennsylvania—Procyon lotor-rabies—raccoon.

\section{Introduction}

$\mathbf{M}$ ULTIPLE RABIES VIRUS VARIANTS continue to be major threats to human, livestock, and wildlife health throughout the United States and many regions of the world. Within the United States, about $90 \%$ of rabies cases that are reported annually to the Centers for Disease Control and Prevention now occur in wildlife (Blanton et al. 2009). There are currently several terrestrial rabies virus variants recognized within the United States; the most prevalent of these variants is associated with raccoons, Procyon lotor (Blanton et al. 2009).

Raccoon rabies has been established in Pennsylvania since the 1980s, and has spread throughout most of the east coast of the United States (Krebs et al. 2002). The first reported cases of raccoon rabies within Pennsylvania were in Bedford, Fulton, and Franklin Counties, which are located within the south-central portion of the ridge-and-valley system (USDA 2004). Notably, early in this outbreak of rabies in raccoons a main corridor of rabies diffusion was suspected through the ridge-and-valley system of this region (Moore 1999).
The Wildlife Services, Animal and Plant Health Inspection Service, U.S. Department of Agriculture, has established cooperative oral rabies vaccination (ORV) programs within multiple states in the United States (NRMP 2008). ORV programs for raccoons are common in much of the eastern United States (NRMP 2008) and ORV operations have been conducted in Pennsylvania since 2001 (USDA 2004).

Raboral V-RG ${ }^{\circledR}$ is the only licensed oral rabies vaccine for wildlife in the United States. Because large expenses are involved in these types of campaigns (USDA 2004), it is important that all key factors that could enhance these efforts be addressed. Recently, Root et al. (2009) suggested that there was little genetic differentiation among raccoon populations associated with a ridge and corresponding valleys in southwestern Pennsylvania. However, this approach accounted for a long-term, historical perspective. Additional information pertaining to actual short-term (e.g., "real-time") movements of raccoons was warranted, as habitat-specific preferences of reservoir species are thought to be key ORV strategy issues (Slate et al. 2005).

Recent theoretical modeling efforts have indicated that major rivers may act as semipermeable barriers to rabies

\footnotetext{
${ }^{1}$ Pennsylvania Wildlife Services, U.S. Department of Agriculture, Bolivar, Pennsylvania.

${ }^{2}$ National Wildlife Research Center, Wildlife Services, U.S. Department of Agriculture, Fort Collins, Colorado.
} 
propagation (Smith et al. 2002). Additionally, mountains have been suggested as potential physiographic barriers to rabies virus trafficking (Carey et al. 1978, Moore 1999). Elevation and habitat characteristics may be important facets associated with the incidence and distinctiveness of rabies epizootics (Childs et al. 2001). However, few attempts have been made to quantify these variables (Smith et al. 2002).

Information on raccoon use of landscape features, such as travel corridors or natural "barriers" that influence animal movements, can be strategically used for control efforts. The geography of Pennsylvania and surrounding states exhibits physical characteristics that may influence movements of raccoons. In addition, this general physiographic region has been thought to historically represent a prominent enzootic area of rabies in nearby states (Linebeck 1980). As such, information pertaining to raccoon movements in this region could enhance ORV strategies by targeting resources in key areas. Therefore, the objective of this study was to describe natural hindrances and/or travel corridors of raccoon movement within ridges and valleys of Pennsylvania. The results of this study may have applications in Pennsylvania and in other eastern states with similar geographic features.

\section{Materials and Methods}

\section{Study sites}

The study site for this project was centered on Laurel Ridge (LR) and two adjacent valleys, referred to hereinafter as Laurel Valley (LV) and Jennerstown Valley (JV; Fig. 1). LR and LV were separated by $6.7 \mathrm{~km}, \mathrm{LR}$ and JV by $9.1 \mathrm{~km}$, and JV and LV by $14.9 \mathrm{~km}$. For clarity, it should be noted that LV and JV are titled for towns within proximity of the study sites. The study area is located near the western edge of the true ridge-and-valley system. Its similar landscape features of long

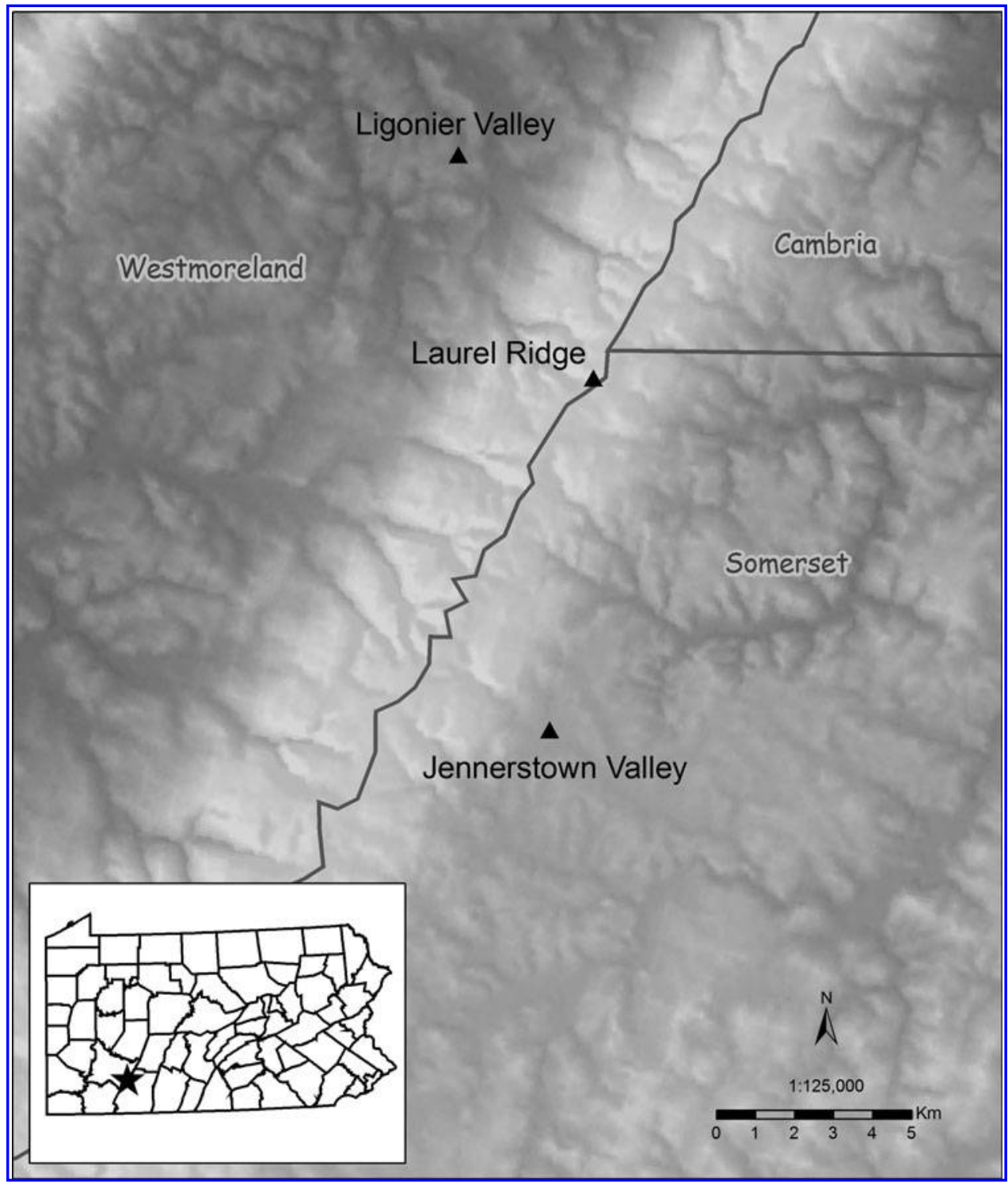

FIG. 1. Centroids of raccoon locations by study site for a movement study on and near Laurel Ridge (Hill), southwestern Pennsylvania. Minimum and maximum distances among these sites were 6.7 and $14.9 \mathrm{~km}$, respectively. Minimum elevation of locations in the valley sites ranged from 335 to $471 \mathrm{~m}$; maximum elevation of locations from the ridge site was $874 \mathrm{~m}$. Inset represents study site location within the state of Pennsylvania. 
narrow ridges separated by broad valleys (PDCNR 2008), as well as logistical features (access, roads, etc.), provided an ideal area to assess natural hindrances and travel corridors related to raccoon movements in this physiographic region.

\section{Raccoon processing}

Raccoon trapping was conducted at three study sites using live-traps during 2006-2007. Trapping was conducted for three age classes (adult, sub-adult, and juvenile). Traps were placed in areas that exhibited raccoon sign(s) (scat, tracks, etc.), and areas of appropriate raccoon habitat (e.g., riparian). Trapping efforts on LR were predominately at the ridge-top to ensure that the majority of these animals were exclusively attributed to this study site (LR) at their time of capture.

Raccoons were anesthetized with an intramuscular injection of a 5:1 mixture of ketamine-xylazine. Before release each animal was weighed, sexed, aged, ear-tagged, and examined for abnormalities. Overall, 22 adult raccoons were equipped with Advanced Telemetry Systems (Isanti, MN) model 1950 transmitters; 8 juvenile and 19 sub-adult raccoons were equipped with ATS model M1235 VHF transmitters for this study. All transmitters were equipped with mortality sensors. Due to a variety of issues, data are presented on these animals for a maximum of $<7$ months for any given cohort. On average, data are reported for 4.6 months (range: 2.1-5.8) for adults, 3.2 months (range: 0.25.3) for sub-adults, and 3.6 months (range: 2.0-6.9) for juveniles. Adult raccoons were followed from late spring/early summer to late fall, sub-adults were followed spring to late summer/early fall, and, in general, juveniles were followed late summer to fall, although a few individuals were followed into the early winter.

\section{Movement assessments}

Raccoons were monitored with an ATS R2000 challenger receiver (Advanced Telemetry Systems) with a three-element folding yagi antenna. Estimated locations for each animal were determined through telemetry and triangulation. Universal Transverse Mercator coordinates were recorded using a hand-held Global Positioning System unit (position accuracy $<10 \mathrm{~m}$, typical) equipped with a digital compass to record bearing azimuths. Typically, one or more locations per animal per week were obtained, as logistics permitted. Due to the scope of this project (e.g., long distance movements over a potential physiographic barrier), locations were collected during both day and evening.

Data were imported into a computer database using location of a signal software (LOAS) to determine estimated locations and associated error ellipses for all raccoon locations. All individual locations with an error ellipse $>5.0$ ha were discarded from downstream analyses. This discard criterion is similar to those that have been previously reported for this species (e.g., Beasley et al. 2007). These locations were then imported into a Geographic Information Systems (GIS) database for mapping and other analyses. We used ArcGIS 9.1 to describe the areas traveled by raccoons.

\section{Results}

The movements of 49 raccoons of three age classes (adult, sub-adult, and juvenile) were assessed at three study sites
Table 1. Summary of the Number of Raccoons

(Procyon lotor) Monitored by Study Site, Age, and Sex (M/F) During a Movement Study Associated with Laurel Ridge and Adjacent Valleys

\begin{tabular}{lcccl}
\hline Study site & Adult & Sub-adult & Juvenile & Sex \\
\hline JV & 3 & 5 & 1 & $\mathrm{M}$ \\
& 3 & 1 & 3 & $\mathrm{~F}$ \\
LR & 8 & 6 & - & $\mathrm{M}$ \\
& 1 & 1 & 1 & $\mathrm{~F}$ \\
LV & 4 & 5 & 1 & $\mathrm{M}$ \\
& 3 & 1 & 2 & $\mathrm{~F}$ \\
Total & 22 & 19 & 8 & \\
\hline
\end{tabular}

Data associated with 740 location points are reported.

JV, Jennerstown Valley; LR, Laurel Ridge; LV, Laurel Valley.

(Table 1; Fig. 1). A total of 740 locations within the three study sites were used to determine potential travel corridors for this species in this physiographic region.

Overall, the three populations studied had little interaction over the short-term, as no valley-to-valley movements were observed during the duration of this study (Fig. 1). However, some ridge-associated raccoons moved down the slope and appeared to encroach upon the adjacent the valleys. In addition, valley-associated animals occasionally moved to the base of the ridge.

The geographic distances that raccoons moved at the three study sites were unremarkable during the study period. Nonetheless, a consistent pattern was noted during this study in that the average maximum distance moved was highest for all age classes on LR when compared to LV and JV. For example, the average maximum distances moved for adults were $2.63 \mathrm{~km}$ on LR, $1.41 \mathrm{~km}$ in JV, and $1.36 \mathrm{~km}$ in LV. For subadults, average maximum distances moved were $1.78 \mathrm{~km}$ on LR, $1.30 \mathrm{~km}$ in JV, and $1.23 \mathrm{~km}$ in LV. Although small sample sizes were obtained, a similar trend was noted for juvenile raccoons, with the maximum average distance moved being obtained from LR. For all age classes, the individuals that moved the greatest maximum distances were males (overall average $1.74 \mathrm{~km}$ for males and $1.54 \mathrm{~km}$ for females). Two adult raccoons associated with this study were found to have rabies during the study period. However, the movements of these raccoons did not differ from the movements of their uninfected counterparts. This observation is consistent with Rosatte et al. (2006), who noted that the movements of rabid and nonrabid raccoons did not differ at their study site in Ontario.

Spur valleys (small valleys on ridges generally situated perpendicular to ridge tops [e.g., ridge drainages into the adjacent valleys]; Fig. 2) were the most notable landscape feature associated with raccoon movements on ridges. Several raccoons used these landscape features substantially. Thus, these spur valleys on ridge slopes may represent commonly used travel corridors for these animals on ridges and may represent a conduit to adjacent valley raccoon populations (Fig. 2).

\section{Discussion}

The spread of rabies is thought to occur throughout a landscape by direct contact of infected animals within a specific area, movement of the virus by infected animals into bordering areas, or through long distance movements by 


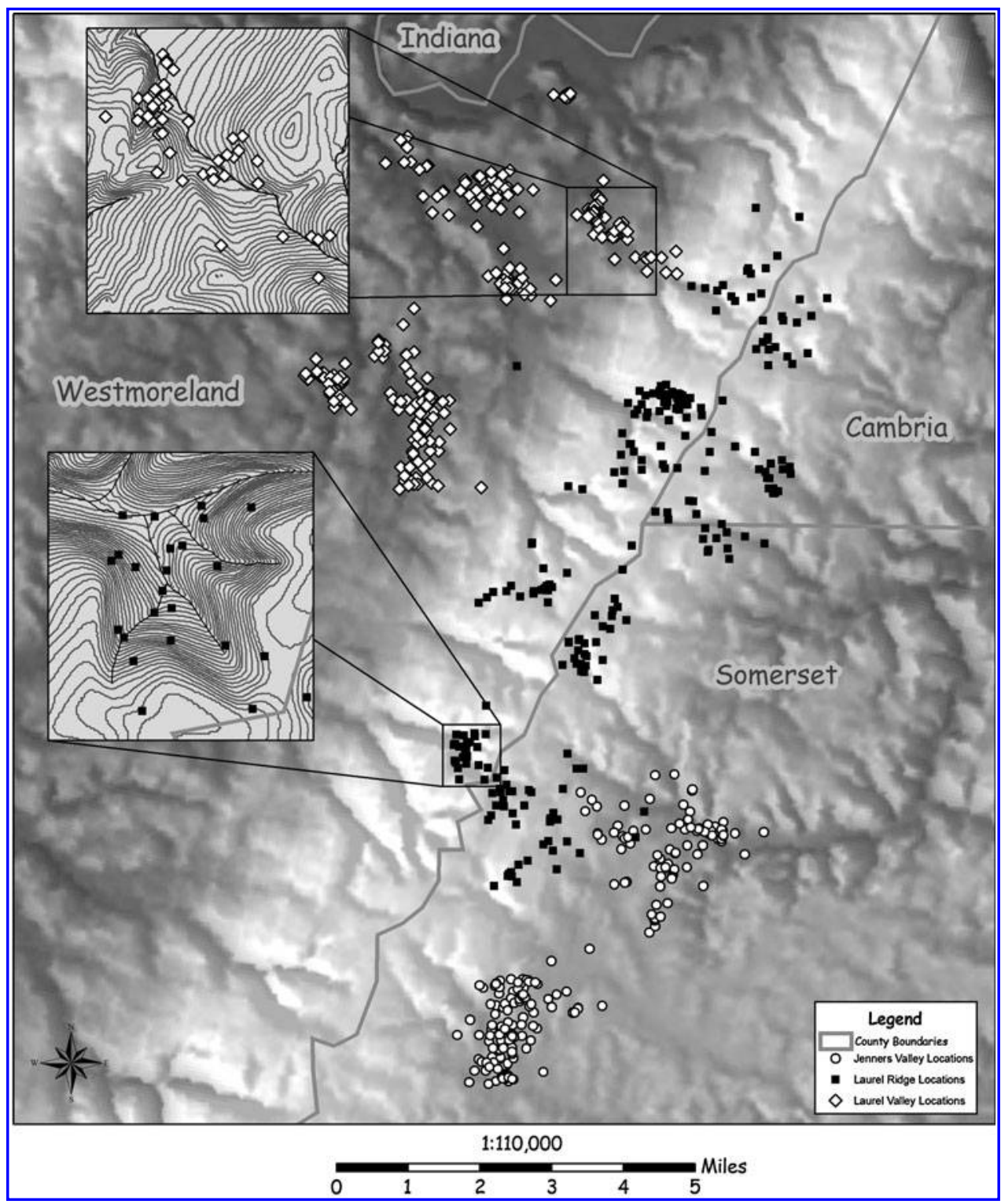

FIG. 2. Location data points from raccoons on and near Laurel Ridge (Hill), southwestern Pennsylvania. Detailed insets highlight the observation of raccoon use of spur valleys as movement corridors on Laurel Ridge.

animals carrying the pathogen to new areas (e.g., temporary or permanent dispersal; Holmala and Kauhala 2006). As such, efforts centered toward rabies containment must recognize routes of wildlife movement, particularly if they are in corridors (Linebeck 1980). Movement data from this study suggest that the ridge we studied may serve as a hindrance to raccoon movements; however, it is not an impenetrable barrier. For example, during this study no raccoons were documented to cross the ridge to move to a different valley. The movements of select raccoons captured on the ridge site encroached the adjacent valleys; however, these animals typically moved back to the ridge. Similar movement shifts have been noted for raccoons in Illinois (Prange et al. 2004). In addition, raccoons captured within the valley sites were observed to move to within the base of the ridge. Both of these movement patterns were typically linked to the smaller valleys that spurred from the main ridge site (Fig. 2). Several published accounts have suggested that raccoons use many den sites and/or rarely reuse den sites regularly (e.g., Fritzell 1978, Lotze and Anderson 1979). This apparent lack of rest site fidelity may be related to home range size and the distance of nightly movements, because as nocturnal movements increase, it will likely become increasingly difficult to return to a recent rest site (Gehrt 2003). Nonetheless, this is not the case with all raccoons at all locations (Rabinowitz and Pelton 1986), as some animals (e.g., females with litters) will likely return to the same den each night (Gehrt 2003).

Our observations of raccoon movements are similar to those reported elsewhere. For example, Arjo et al. (2008) reported adult and sub-adult male raccoon movements in Alabama of several kilometers (maximum $>5.4 \mathrm{~km}$ ) and adult females moving up to $3.5 \mathrm{~km}$. However, farther movements (e.g., $24 \mathrm{~km}$ ) have been reported for this species (Rosatte et al. 2007). In this study, farther movements in continuous 
forested habitat (e.g., the ridge site) were observed more frequently when compared to raccoon movements within proximity to humans or agriculture (valley sites). Similarly, previous studies have found larger home ranges of raccoons within a forested landscape when compared to suburban and rural landscapes (Prange et al. 2004), and greater movement distances for male raccoons when compared to females (Rosatte et al. 2007). Of interest, previous research has suggested that counties with a greater percentage of mixed forest habitat were less likely to experience large rabies epizootics than counties with a lower percentage of mixed forest habitat (Jones et al. 2003).

Overall, the animals we monitored in the valley sites had limited movements, which suggests that these animals may have had access to abundant resources. Areas of unnatural food sources were observed near the edge of the LR and LV sites. Numerous locations of study animals were recorded at these sites, suggesting that the movement patterns of these animals may have been influenced by these unnatural resources. Notably, the abundance and distribution of sustenance resources is thought to greatly affect the movements and spatial distribution of certain small carnivores (Prange et al. 2004).

Only short distance movements (average $=1.61 \mathrm{~km}$ ) were noted for juvenile raccoons during late summer/fall (e.g., August-November), which suggests that juvenile raccoons may remain in their natal areas for some time before dispersal. In addition, these distances were similar (average $=1.47 \mathrm{~km}$ ) for sub-adult raccoons (e.g., raccoons surviving their first full winter) during the spring, suggesting that raccoons do not tend to disperse very far in this region. This is auspicious, as dispersal is thought to be a critical element for the spread of rabies, as dispersing juveniles may carry the virus to new areas (Holmala and Kauhala 2006).

The results of this study describe LR as a potential natural hindrance to raccoon movement over the short-term, which could potentially slow the spread of the raccoon rabies virus variant. Travel corridors of raccoon movements between the valley sites to the ridge were largely identified as spur valleys. Thus, these spur valleys on ridge slopes may represent commonly used travel corridors for these animals on ridges and may represent a conduit to adjacent valley raccoon populations (Fig. 2). However, these results should be interpreted with caution over the long-term, as a landscape genetics study of raccoons conducted in the same general area suggested that there was one essentially panmictic population of these animals in this area with no obvious hindrances or corridors to movement (Root et al. 2009). Thus, although this study suggests that raccoons seldom move from one valley to the next over the short-term, it most certainly happens on occasion. In addition, these populations likely interact at habitat interfaces. Although some evidence of isolation by distance has been noted for raccoons in this area (Root et al. 2009), raccoons do not necessarily need to disperse into other areas (e.g., one valley to another) to develop a panmictic population or to transmit rabies virus. For example, if raccoons from LV come into contact with raccoons on LR, and those raccoons in turn come into contact with raccoons from JV, these interactions could produce a seemingly panmictic population and enable rabies virus transmission among the three populations.

In summary, this study suggests that patterns of raccoon movements within select ridges and valleys of Pennsylvania can be linked to travel corridors between these landscapes. Overall, small spur valleys that tend to run perpendicular to ridge tops yielded evidence as the most important travel corridors for raccoons between these two landscape types. These landscape features could be valuable for strategic rabies management and may warrant an area of additional study.

\section{Acknowledgments}

We are indebted to A. Hess, B. Zahuranic, E. Swope, J. Duncan, T. Roland, and other Pennsylvania Wildlife Services personnel for trapping and logistical assistance. We thank C. Fulcomer for veterinary services, K. MacCarthy for trapping assistance, and many public and private land stewards for allowing us access to their lands. In addition, we thank many Pennsylvania Game Commission personnel for their assistance in this study, and J. Larkin for assistance with aerial telemetry and equipment loans. Funding for this work was provided by the U.S. Department of Agriculture.

\section{Disclosure Statement}

No competing financial interests exist.

\section{References}

Arjo, WM, Fisher, CE, Armstrong, J, Boyd, F, Slate, D. Effects of natural barriers and habitat on the western spread of raccoon rabies in Alabama. J Wildl Manage 2008; 72:1725-1735.

Beasley, JC, DeVault, TL, Retamosa, MI, Rhodes, OE. A hierarchical analysis of habitat selection by raccoons in northern Indiana. J Wildl Manage 2007; 71:1125-1133.

Blanton, JD, Robertson, K, Palmer, D, Rupprecht, CE. Rabies surveillance in the United States during 2008. J Am Vet Med Assoc 2009; 235:676-689.

Carey, AB, Giles, RH, McLean, RG. The landscape epidemiology of rabies in Virginia. Am J Trop Med Hyg 1978; 27:573-580.

Childs, JE, Curns, AT, Dey, ME, Real, LA, et al. Rabies epizootics among raccoons vary along a north-south gradient in the eastern United States. Vector Borne Zoonot Dis 2001; 1:253267.

Fritzell, EK. Habitat use by prairie raccoons during the waterfowl breeding season. J Wildl Manage 1978; 42:118-127.

Gehrt, SD. Raccoon (Procyon lotor and allies). In: Fledhamer, GA, Thompson, BC, Champman, JA, eds. Wild Mammals of North America: Biology, Management, and Conservation. Baltimore, MD: The John Hopkins University Press, 2003:611-634.

Holmala, K, Kauhala, K. Ecology of wildlife rabies in Europe. Mammal Rev 2006; 36:17-36.

Jones, ME, Curns, AT, Krebs, JW, Childs, JE. Environmental and human demographic features associated with epizootic raccoon rabies in Maryland, Pennsylvania, and Virginia. J Wildl Dis 2003; 39:869-874.

Krebs, JW, Noll, HR, Rupprecht, CE, Childs, JE. Rabies surveillance in the United States during 2001. J Am Vet Med Assoc 2002; 221:1690-1701.

Linebeck, NG. A model of rabies diffusion. Southeast Geogr 1980; 20:1-15.

Lotze, JH, Anderson, S. Procyon lotor. Mamm Species 1979; 119:1-8.

Moore, DA. Spatial diffusion of raccoon rabies in Pennsylvania, USA. Prev Vet Med 1999; 40:19-32.

[NRMP] National Rabies Management Program. 2008. Available at www.aphis. usda.gov/wildlife_damage/oral_rabies/index .shtml, accessed February 2008. 
[PDCNR] Pennsylvania Department of Conservation and Natural Resources. 2008. Available at www.dcnr.state.pa.us/2008, accessed February 2008. (Online.)

Prange, S, Gehrt, SD, Wiggers, EP. Influences of anthropogenic resources on raccoon movements and spatial distribution. J Mammal 2004; 85:483-490.

Rabinowitz, AR, Pelton, MR. Day-bed use by raccoons. I Mammal 1986; 67:766-769.

Root, JJ, Puskas, RB, Fischer, JW, Swope, CB, et al. Landscape genetics of raccoons (Procyon lotor) associated with ridges and valleys of Pennsylvania: implications for oral rabies vaccination programs. Vector Borne Zoonot Dis 2009; 9:583588.

Rosatte, R, MacDonald, E, Sobey, K, Donovan, D, et al. The elimination of raccoon rabies from Wolfe Island, Ontario: animal density and movements. J Wildl Dis 2007; 43:242250.

Rosatte, R, Sobey, K, Donovan, D, Bruce, L, et al. Behavior, movements, and demographics of rabid raccoons in Ontario, Canada: management implications. J Wildl Dis 2006; 42:589605.
Slate, D, Rupprecht, CE, Rooney, JA, Donovan, D, et al. Status of oral rabies vaccination in wild carnivores in the United States. Virus Res 2005; 111:68-76.

Smith, DL, Lucey, B, Waller, LA, Childs, JE, et al. Predicting the spatial dynamics of rabies epidemics on heterogeneous landscapes. Proc Natl Acad Sci USA 2002; 99:3668-3672.

USDA. Cooperative Rabies Management Program National Report. USDA-AHPIS-Wildlife Services, Concord, New Hampshire. 2004b. Available at www.aphis.usda.gov/wildlife_damage/ prog_data/prog_data.report.shtml

Address correspondence to: J. Jeffrey Root National Wildlife Research Center Wildlife Services

U.S. Department of Agriculture 4101 LaPorte Avenue Fort Collins, CO 80521

E-mail: jeff.root@aphis.usda.gov 